\title{
Características agronômicas de cultivares de trigo em resposta à época da adubação nitrogenada de cobertura
}

\author{
Agronomic characteristics of wheat cultivars in response to the time of nitrogen fertilizer covering
}

\author{
Luís Sangoi ${ }^{I}$ Adelina Cecília Berns ${ }^{\text {II }}$ Milton Luiz de Almeida ${ }^{\mathrm{I}}$ Claitson Gustavo Zanin ${ }^{\mathrm{II}}$ \\ Cleber Schweitzer II
}

\section{RESUMO}

As cultivares de trigo diferem quanto à capacidade de emissão de afilhos, à arquitetura de planta e à duração do ciclo. Estas diferenças podem interferir na determinação da época ideal de aplicação de nitrogênio em cobertura para otimizar a performance agronômica da cultura. Este trabalho objetivou identificar os efeitos de época de realização da adubação nitrogenada de cobertura sobre o acúmulo de matéria seca no colmo principal e nos afilhos, o rendimento de grãos e o teor protéico dos grãos de três cultivares de trigo. O experimento foi conduzido a campo, durante o ano agrícola de 2003, no município de Lages, SC. Foram testadas quatro épocas de aplicação de nitrogênio em cobertura: estádios 3,5, 5,5, 7,5 e emborrachamento da escala de Haun; e três cultivares de trigo, "BRS 179", “Fundacep 36” e "Rubi”. O ensaio foi implantado sobre resteva de feijão, em 11/07/2003. A dose total de $\mathrm{N}$ utilizada no trabalho foi de $70 \mathrm{~kg} \mathrm{ha}^{-1}$, sendo $20 \mathrm{~kg}$ $\mathrm{ha}^{-1}$ aplicados na semeadura e o restante em cobertura, conforme a época definida em cada tratamento. Independentemente das características da cultivar, as aplicações precoces de $N$, realizadas nos estádios 3,5 e 5,5 da escala de Haun, propiciaram a obtenção dos maiores valores de rendimento de grãos. Quando o nitrogênio foi aplicado nestas épocas, houve maior contribuição percentual dos afilhos ao rendimento e maior número de grãos produzidos por área. A cultivar "Fundacep 36" foi a mais produtiva e também a que externou menor teor de proteína nos grãos, na média das quatro épocas de aplicação de nitrogênio em cobertura. Não houve efeito da época de aplicação do nitrogênio sobre o teor de proteína nos grãos das cultivares avaliadas.

Palavras-chave: Triticum aestivum, nitrogênio, genótipo, rendimento de grãos, teor de proteína.

\begin{abstract}
The wheat cultivars differ in terms of tiller emission, plant architecture and growing cycle duration. Such differences may interfere in the ideal period to side-dress $N$ to optimize the crop agronomic performance. This experiment was aimed at identifing the effects of timing of $N$ side-dress on the main stem and tiller dry matter accumulation, grain yield and kernel protein content of three wheat cultivars. A field trial was conducted during the 2003 growing season, in the city of Lages, SC. Nitrogen was applied at four different times: 3,5, 5,5, 7,5 and at booting growth stages of the Haun's Scale. Three cultivars were evaluated: 'BRS 179', 'Fundacep' and 'Rubi'. The experiment was installed over a common bean straw on $07 / 11 / 2003$. The total nitrogen rate was $70 \mathrm{~kg} \mathrm{ha}^{-1}$ with $20 \mathrm{~kg}$ $\mathrm{ha}^{-1}$ being applied at sowing and $50 \mathrm{~kg} \mathrm{ha}^{-1}$ side-dressed according to the treatment time. Regardless of cultivar type, early nitrogen side-dresses, performed at the 3,5 and 5,5 Haun's growth stages, provided higher values of grain yield. When $N$ was applied at those growth stages, tillers had a greater contribution to grain yield and there was a higher number of kernels produced per area. The cultivar Fundacep 36 presented the highest grain yield and the lowest kernel protein content, considering the average of four times of $N$ side-dress. There was no significant effect of time of $N$ fertilization on kernel protein content.
\end{abstract}

Key words: Triticum aestivum, nitrogen, genotype, grain yield, protein content.

\section{INTRODUÇÃO}

O trigo é um dos principais cereais utilizados na alimentação humana, participando com

IDepartamento de Fitotecnia da Universidade do Estado de Santa Catarina (UDESC), Caixa Postal 281, 88520-000, Lages, SC,
Brasil. E-mail:a2ls@cav.udesc.br. Autor para correspondência.

IIAcadêmicos do Curso de Mestrado em Produção Vegetal da UDESC. 
aproximadamente 32\% da produção mundial de grãos (COMISSÃO SUL-BRASILEIRA DE PESQUISA DE TRIGO, 2003). O consumo de trigo no Brasil é de aproximadamente $60 \mathrm{~kg}$ habitante ${ }^{-1}$ ano $^{-1}$, sendo o país um grande importador deste grão, pois sua produção tem oscilado ao redor de 6,0 milhões de toneladas para um consumo potencial de aproximadamente 10 milhões de toneladas (MASCHIO, 2004).

A falta de incentivo à produção, a pequena área cultivada e os baixos tetos de rendimento são fatores que contribuem para o déficit anual na produção brasileira de trigo (MUNDSTOCK, 1999). O estabelecimento de práticas de manejo que otimizem os insumos aplicados pode contribuir para aumentar a produtividade nas lavouras de trigo no Brasil, que tem se situado em valores próximos a $2.000 \mathrm{~kg} \mathrm{ha}^{-1}$ (IBGE, 2004). Dentre essas, a adubação nitrogenada de cobertura é uma das mais importantes, pois afeta o crescimento e o desenvolvimento das plantas, influenciando o seu potencial produtivo.

O nitrogênio ( $\mathrm{N}$ ) é um elemento essencial para as plantas, pois participa de uma série de rotas metabólicas-chave em sua bioquímica, sendo constituinte de importantes biomoléculas, tais como ATP, NADH, NADPH, clorofila, proteínas de armazenamento, ácidos nucléicos e enzimas (HARPER, 1994).

Além de sua importância biológica, o nitrogênio é o nutriente mais difícil de ser manejado nos solos de regiões tropicais e subtropicais, em virtude do grande número de reações a que está sujeito e a sua alta instabilidade no solo (ERNANI, 2003). Em função disso, o parcelamento da adubação nitrogenada proporciona uma maior eficiência na assimilação do nutriente pelo trigo, diminuindo as perdas por lixiviação em anos chuvosos e por volatilização em anos secos (MUNDSTOCK, 1999).

A época correta de aplicação do nitrogênio é fundamental para incrementar o rendimento de grãos, pois aplicações muito precoces ou muito tardias podem ser pouco aproveitadas pelas plantas (SILVA et al., 2005). A aplicação de nitrogênio no momento adequado pode aumentar a eficiência de uso do nitrogênio pelo trigo, incrementando o número de grãos por espiga e o número de espigas por área. Além dos aspectos agronômicos, a fertilização em época apropriada pode reduzir os riscos de poluição das águas subterrâneas ocasionados pelo acúmulo de nitrato (MAHLER et al., 1994).

A maior parte dos trabalhos realizados com época de aplicação do nitrogênio na cultura do trigo tem utilizado apenas uma cultivar. Por outro lado, as cultivares diferem substancialmente na sua capacidade de emissão de afilhos, no seu ciclo, na arquitetura de planta e no potencial produtivo. Estas diferenças podem interferir na capacidade absorção, assimilação e conversão do nitrogênio à produção de grãos. Além disso, a cada ano são lançados novos genótipos que, por apresentarem base genética diferenciada, podem apresentar resposta distinta à dose e à época de aplicação do nitrogênio.

Portanto, a base genética e as características morfofisiológicas da cultivar têm sido pouco enfatizadas nos estudos destinados a definir o momento ideal para aplicação do nitrogênio na cultura do trigo. Dentro desse contexto, conduziu-se este trabalho com o objetivo de estudar o efeito da época de realização da adubação nitrogenada de cobertura sobre o acúmulo de matéria seca na planta, o rendimento de grãos e o teor protéico dos grãos de três cultivares de trigo contrastantes quanto à arquitetura de planta e à capacidade de emissão de afilhos.

\section{MATERIAL E MÉTODOS}

O experimento foi conduzido a campo, durante o ano agrícola de 2003, no município de Lages, localizado no Planalto Sul de Santa Catarina. O solo da área experimental é classificado como Cambissolo Húmico (EMBRAPA, 1999), apresentando, 30 dias antes da instalação do ensaio, valores de $\mathrm{pH}$ em água e de matéria orgânica de 6,1 e $38 \mathrm{~g} \mathrm{~kg}^{-1}$, respectivamente.

O delineamento experimental utilizado foi o de blocos casualizados, no esquema fatorial, com seis repetições. Cada parcela foi consituída de 10 linhas, com $5 \mathrm{~m}$ de comprimento e espaçamento entre linhas de 0,20m. Foram testadas quatro épocas de aplicação de nitrogênio em cobertura: estádio 3,5 (três folhas totalmente expandidas e a quarta com $50 \%$ do tamanho da terceira), 5,5, 7,5 e emborrachamento da escala proposta por HAUN (1973). Para cada época de aplicação do nitrogênio, foram avaliadas três cultivares de trigo: “BRS 179”, “Fundacep 36” e "Rubi”. Estas cultivares apresentam características contrastantes quanto a ciclo, estatura e capacidade de afilhamento. A cultivar “BRS 179” possui hábito vegetativo semi-ereto a ereto, estatura média a alta (aproximadamente $120 \mathrm{~cm}$ ) e é moderadamente suscetível ao acamamento. A cultivar “Fundacep 36” possui baixa estatura (menor do que $90 \mathrm{~cm}$ ) e resistência ao acamamento. A cultivar “Rubi” possui hábito vegetativo semiprostrado, afilhamento intenso, estatura média (aproximadamente $90 \mathrm{~cm})$, sendo moderadamente suscetível ao acamamento (COMISSÃO SUL-BRASILEIRA DE PESQUISA DE TRIGO, 2003). 
A adubação foi feita com base nos resultados obtidos na análise de solo realizada 30 dias antes da semeadura e nas recomendações da COMISSÃO DE FERTILIDADE DE SOLO-RS/SC (1995). Aplicaram-se $80 \mathrm{~kg} \mathrm{ha}^{-1}$ de $_{2} \mathrm{O}_{5}$ e $50 \mathrm{~kg}$ de $\mathrm{K}_{2} \mathrm{O}$ na semeadura, visando a obterem-se produtividades maiores que $2.000 \mathrm{~kg} \mathrm{ha}^{-1}$. A quantidade de nitrogênio aplicada foi determinada com base no teor de matéria orgânica do solo. Na semeadura, aplicaram-se $20 \mathrm{~kg} \mathrm{ha}^{-1}$ e, em cobertura, $50 \mathrm{~kg} \mathrm{ha}^{-1}$ de nitrogênio, na forma de uréia.

A semeadura foi realizada sobre resteva de feijão, no dia 11/07/03, utilizando-se uma semeadoraadubadora de parcelas, na densidade de 300 sementes aptas $\mathrm{m}^{-2}$. A emergência das plantas ocorreu no dia 20/ 07/03. As coberturas nitrogenadas foram aplicadas nos dias 06/08, 22/08, 10/09 e 29/09/03, respectivamente, para os estádios 3,5, 5,5, 7,5 e emborrachamento da escala HAUN (1973).

O controle de plantas daninhas foi efetuado com o herbicida metsulforon-metil (Ally), na dose de $4 \mathrm{~g} \mathrm{ha} \mathrm{h}^{-1}$ do produto comercial, quando as plantas de trigo estavam no estádio 3,5 da escala proposta por HAUN (1973) e com capinas adicionais sempre que necessário. Também foi realizado o controle de oídio (Blumeria graminis f.sp. tritici) e de pulgões, feitos, respectivamente, através da aplicação de metconazole (Caramba $90 \mathrm{SL}$ ) e metamidofós (Tamaron BR), nas doses de $1,0 \mathrm{~L} \mathrm{ha}^{-1}$ e $0,2 \mathrm{~L} \mathrm{ha}^{-1}$, em 7/10/03, quando as plantas estavam no emborrachamento.

Para avaliar o efeito dos tratamentos sobre o acúmulo de matéria seca e a capacidade de afilhamento das cultivares, foram realizadas seis coletas de plantas, em 12/09, 03/10, 17/10, 31/10, 14/11 e 28/11. Em cada época, coletaram-se plantas numa área de $0,5 \mathrm{~m}$ lineares de cada parcela. As plantas foram separadas em colmo principal (CP) e afilhos (AF), acondicionadas em sacos de papel e secadas em estufa de fluxo de ar contínuo a aproximadamente $60^{\circ} \mathrm{C}$, até atingirem massa constante. O material foi pesado, obtendo-se as matéria ssecas do colmo principal e dos afilhos, que foram utilizadas para calcular a matéria seca total (somatório da matéria seca de CP e AF).

A colheita das plantas para a determinação do rendimento de grãos e componentes ocorreu no dia 06/12. Foram colhidas manualmente as linhas 2, 3, 4 e 5 das parcelas, descartando-se $0,5 \mathrm{~m}$ em cada extremidade da linha, totalizando uma área útil de $3,2 \mathrm{~m}^{2}$. O material colhido foi limpo, trilhado e secado até atingir massa constante para determinação do rendimento de grãos, que foi expresso na umidade padrão de $13 \%$. Para determinação dos componentes do rendimento, utilizaram-se as linhas 7, 8 e 9 das parcelas, onde colheu- se $0,5 \mathrm{~m}$. Neste material, determinou-se o número de espigas $\mathrm{m}^{-2}$, o número de grãos por espiga, o número de grãos $\mathrm{m}^{-2} \mathrm{e}$ a massa de 1.000 grãos.

O conteúdo de nitrogênio nos grãos foi determinado utilizando-se uma amostra de $100 \mathrm{~g}$ de grãos da área útil. Estes grãos foram moídos em moinhos do tipo centrífuga, com peneira de $0,2 \mathrm{~mm}$ de diâmetro. Para a determinação do nitrogênio total presente nos grãos, empregou-se a metodologia descrita por TEDESCO et al. (1995), utilizando-se o fator de conversão de 6,25 para o cálculo da proteína bruta presente nos grãos.

Os dados obtidos foram submetidos à análise de variância, utilizando-se o teste F. As médias de aplicação de $\mathrm{N}$ em cobertura e das cultivares foram comparadas pelo teste de Duncan, ao nível de 5\% de probabilidade de erro $(\mathrm{P}<0,05)$.

\section{RESULTADOS E DISCUSSÃO}

A interação entre a época de aplicação de nitrogênio e a cultivar influenciou significativamente o acúmulo total de matéria seca no CP e nos afilhos, na média das seis amostragens realizadas (Tabela 1). Para a cultivar "Fundacep 36”, o maior acúmulo de matéria seca no colmo principal ocorreu quando o nitrogênio foi aplicado nos estádios 5,5 e 7,5 da escala HAUN(1973). Não houve efeito de época de aplicação de $\mathrm{N}$ em cobertura sobre a alocação de matéria seca no CP da cultivar "Rubi", enquanto que a cultivar "BRS 179" alocou mais fitomassa no $\mathrm{CP}$ quando o $\mathrm{N}$ foi aplicado em 5,5. A cultivar "BRS 179" alocou mais matéria seca ao CP do que as demais cultivares quando o nitrogênio em cobertura foi aplicado nos estádios iniciais de crescimento (3,5 e 5,5).

O maior acúmulo de matéria seca nos afilhos ocorreu quando o nitrogênio foi aplicado nos estádios iniciais de desenvolvimento, especialmente no estádio 3,5 da escala proposta por HAUN (1973) (Tabela 1), confirmando as observações de ABDIN et al. (1996) de que a aplicação de $\mathrm{N}$ nos estádios iniciais de desenvolvimento estimula o acúmulo de MS pelos afilhos. A cultivar "Rubi” alocou mais matéria seca nos afilhos do que a cultivar "BRS 179” em todas as épocas de aplicação do $\mathrm{N}$ em cobertura, com exceção daquela feita no estádio 5,5 da escala Haun, na qual não houve diferenças significativas entre as duas cultivares.

Houve efeito significativo da época de aplicação do nitrogênio em cobertura sobre o rendimento de grãos das cultivares (Tabela 2). Na média das três cultivares, a aplicação de N no estádio de 5,5 folhas propiciou o maior valor de rendimento de grãos, não diferindo do estádio 3,5. A cultivar "Fundacep 36" 
Tabela 1 - Matéria seca do colmo principal e dos afilhos de três cultivares de trigo, em quatro épocas de aplicação de nitrogênio em cobertura, na média de seis amostragens. Lages, SC, 2003.

\begin{tabular}{|c|c|c|c|c|}
\hline Éроса & Fundacep 36 & Rubi & BRS 179 & Média \\
\hline & \multicolumn{4}{|c|}{ Matéria seca do colmo principal } \\
\hline & & 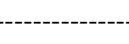 & -------------- & --- \\
\hline $3,5^{1 /}$ & $378 \mathrm{~b} \mathrm{~B}^{2 /}$ & 359 b A & 473 a B & 402 \\
\hline 5,5 & $437 \mathrm{~b} \mathrm{~A}$ & 370 с A & 547 a A & 451 \\
\hline 7,5 & 456 a A & 361 b A & 439 а BC & 419 \\
\hline Emborr. & 373 ab B & 344 b A & 406 a C & 374 \\
\hline Média & 410 & 358 & 466 & 411 \\
\hline \multirow[t]{2}{*}{ CV (\%) } & \multicolumn{4}{|c|}{8,6} \\
\hline & \multicolumn{4}{|c|}{ Matéria seca dos afilhos } \\
\hline 3,5 & 229,4 b AB & 305,0 a A & 222,5 b A & 252,3 \\
\hline 5,5 & 260,6 a A & 214 ab B & 203,1 b AB & 225,8 \\
\hline 7,5 & 141,1 b C & 235,0 a B & 163,3 b BC & 179,8 \\
\hline Emborr. & 182,2 a BC & 197,5 a B & 116,9 b C & 165,6 \\
\hline Média & 203,3 & 237,8 & 176,5 & 205,8 \\
\hline CV (\%) & \multicolumn{4}{|c|}{9,8} \\
\hline
\end{tabular}

${ }^{1 /}$ Estádios 3,5, 5,5, 7,5 e emborrachamento da escala proposta por HAUN (1973).

${ }^{2 /}$ Médias seguidas pela mesma letra minúscula (entre cultivares em cada época) e maiúscula (entre épocas para cada cultivar) na linha não diferem estatisticamente pelo Teste de Duncan a 5\% de probabilidade de erro.

foi a mais produtiva e a "Rubi” a que externou o menor rendimento de grãos, na média das quatro épocas de aplicação de nitrogênio em cobertura.

A aplicação de $\mathrm{N}$ no emborrachamento propiciou a obtenção de grãos mais pesados do que quando a cobertura foi feita no estádio 3,5 da escala proposta por HAUN (1973) (Tabela 3). Por outro lado, a última época de realização de cobertura foi a de menor resposta ao rendimento de grãos, mostrando baixa associação entre rendimento e massa de grãos. Estes

Tabela 2 - Contribuição dos afilhos à produtividade e ao rendimento de grãos de três cultivares de trigo, em quatro épocas de aplicação de nitrogênio em cobertura. Lages, SC, 2003.

\begin{tabular}{|c|c|c|c|c|}
\hline Época & Fundacep 36 & Rubi & BRS 179 & Média \\
\hline & \multicolumn{4}{|c|}{ Contribuição dos afilhos a produtividade } \\
\hline $3,5^{1 /}$ & $42,4 \mathrm{~ns}^{2 /}$ & 43,6 & 25,2 & $37,1 \mathrm{~A}^{3 /}$ \\
\hline 5,5 & 35,3 & 32,1 & 31,2 & $32,9 \mathrm{AB}$ \\
\hline 7,5 & 26,5 & 35,1 & 22,7 & $28,1 \mathrm{~B}$ \\
\hline Emborr. & 29,7 & 32,6 & 17,1 & $26,5 \mathrm{~B}$ \\
\hline Média & 33,49 a & 35,86 a & $24,04 \mathrm{~b}$ & \\
\hline \multirow[t]{3}{*}{ CV (\%) } & \multicolumn{4}{|c|}{10,2} \\
\hline & \multicolumn{4}{|c|}{ Rendimento de grãos } \\
\hline & & ---- & umidade & --------- \\
\hline 3,5 & $3.689 \mathrm{~ns}$ & 2.794 & 3.254 & $3.246 \mathrm{AB}$ \\
\hline 5,5 & 4.001 & 3.025 & 3.454 & $3.493 \mathrm{~A}$ \\
\hline 7,5 & 3.460 & 2.945 & 3.048 & $3.151 \mathrm{BC}$ \\
\hline Emborr. & 3.277 & 2.627 & 2.755 & $2.886 \mathrm{C}$ \\
\hline Média & 3.607 a & $2.848 \mathrm{c}$ & $3.128 \mathrm{~b}$ & \\
\hline CV (\%) & \multicolumn{4}{|c|}{7,6} \\
\hline
\end{tabular}

${ }^{1 /}$ Estádios 3,5, 5,5, 7,5 e emborrachamento da escala proposta por HAUN (1973).

${ }^{2 /}$ ns: diferença não-significativa.

${ }^{3 /}$ Médias seguidas pela mesma letra minúscula na linha e pela mesma letra maiúscula na coluna não diferem estatisticamente pelo Teste de Duncan a 5\% de probabilidade de erro. 
Tabela 3 - Componentes do rendimento de três cultivares de trigo, em quatro épocas de aplicação de nitrogênio em cobertura. Lages, SC, 2003.

\begin{tabular}{|c|c|c|c|c|}
\hline Éроса & Fundacep 36 & Rubi & BRS 179 & Média \\
\hline & \multicolumn{4}{|c|}{ Espigas $\mathrm{m}^{-2}$} \\
\hline 3,5 & 478 ns & 562 & 412 & $484 \mathrm{AB}$ \\
\hline 5,5 & 512 & 598 & 463 & $524 \mathrm{~A}$ \\
\hline 7,5 & 392 & 510 & 450 & $450 \mathrm{~B}$ \\
\hline Emborr. & 420 & 550 & 515 & $495 \mathrm{AB}$ \\
\hline Média & $450 \mathrm{~b}$ & 555 a & $460 \mathrm{~b}$ & \\
\hline \multirow[t]{2}{*}{ CV (\%) } & \multicolumn{4}{|c|}{6,5} \\
\hline & \multicolumn{4}{|c|}{ Grãos espiga $^{-1}$} \\
\hline $3,5^{1 /}$ & $21 \mathrm{~ns}^{2 /}$ & 15 & 19 & $18 \mathrm{~A}^{3 /}$ \\
\hline 5,5 & 21 & 13 & 18 & $17 \mathrm{AB}$ \\
\hline 7,5 & 23 & 16 & 17 & $18 \mathrm{~A}$ \\
\hline Emborr. & 20 & 14 & 12 & $15 \mathrm{~B}$ \\
\hline Média & $21 \mathrm{a}$ & $14 \mathrm{c}$ & $16 \mathrm{~b}$ & \\
\hline \multirow[t]{2}{*}{ CV (\%) } & \multicolumn{4}{|c|}{11,2} \\
\hline & \multicolumn{4}{|c|}{ Grãos m ${ }^{-2}$} \\
\hline 3,5 & $9.993 \mathrm{~ns}$ & 8.083 & 7.675 & $8.584 \mathrm{AB}$ \\
\hline 5,5 & 10.690 & 8.013 & 8.165 & $8.956 \mathrm{~A}$ \\
\hline 7,5 & 8.949 & 8.098 & 7.058 & 8.035 BC \\
\hline Emborr. & 8.263 & 7.159 & 6.463 & $7.295 \mathrm{C}$ \\
\hline Média & 9.474 a & $7.838 \mathrm{~b}$ & $7.340 \mathrm{~b}$ & \\
\hline \multirow[t]{3}{*}{ CV (\%) } & \multicolumn{4}{|c|}{10,7} \\
\hline & \multicolumn{4}{|c|}{ Massa de mil grãos } \\
\hline & ----- & 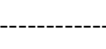 & de ---------- & ----- \\
\hline 3,5 & $37,28 \mathrm{~ns}$ & 34,45 & 42,37 & 38,03 B \\
\hline 5,5 & 37,48 & 38,22 & 42,25 & $39,32 \mathrm{AB}$ \\
\hline 7,5 & 38,70 & 36,47 & 43,18 & $39,45 \mathrm{AB}$ \\
\hline Emborr. & 39,65 & 36,67 & 42,72 & 39,68 A \\
\hline Média & $38,28 \mathrm{~b}$ & 36,45 c & 42,63 a & \\
\hline CV (\%) & & & & \\
\hline
\end{tabular}

\footnotetext{
${ }^{1 /}$ Estádios 3,5, 5,5, 7,5 e emborrachamento da escala proposta por HAUN (1973).

2/ns: diferença não-significativa

${ }^{3 /}$ Médias seguidas pela mesma letra minúscula na linha e pela mesma letra maiúscula na coluna não diferem estatisticamente pelo Teste de Duncan a $5 \%$ de probabilidade de erro.
}

dados corroboram as observações de DIDONET et al. (2000), de que o aumento da massa de grãos está normalmente associado a uma disponibilidade maior de $\mathrm{N}$ durante a fase de floração e o início do enchimento de grãos. Por outro lado, grãos com maior massa não garantem necessariamente maior produtividade por área à cultura do trigo. A cultivar "BRS 179" foi a que apresentou grãos mais pesados na colheita, na média das quatro épocas de aplicação de nitrogênio.

A aplicação precoce do nitrogênio em cobertura (estádios 3,5 e 5,5) estimulou uma maior produção de grãos por área do que com as coberturas mais tardias (Tabela 3), o que contribuiu para os maiores valores de rendimento de grãos obtidos nestas épocas (Tabela 2). A massa de grãos é importante para a determinação do rendimento de grãos em condições que resultam num baixo número de colmos $\mathrm{m}^{-2}$ (OKUYAMA, 2004). Por outro lado, sob altas densidades, o número de espigas $\mathrm{m}^{-2}$ é o componente do rendimento mais importante. Os resultados obtidos neste trabalho demonstraram que a cultivar mais produtiva, “Fundacep 36”, foi também a que produziu maior número de grãos por espiga e por área (Tabelas 2 e 3). A cultivar "Rubi" destacou-se com relação à produção de espigas por área, mas produziu poucos grãos por espiga, o que limitou a produção de grãos $\mathrm{m}^{-2} \mathrm{e}$, 
conseqüentemente, o rendimento de grãos. Isso confirmou as ponderações de DIDONET et al. (2000) de que a produção de grãos por área apresenta maior correlação com a produtividade da cultura do que a massa de grãos, pois ela associa dois componentes do rendimento, o número de espigas por área e o número de grãos por espiga.

A aplicação precoce do nitrogênio em cobertura estimulou a contribuição dos afilhos no rendimento final (Tabela 2). Quando o $\mathrm{N}$ foi aplicado no estádio 3,5 da escala HAUN (1973), estas estruturas contribuíram com 37,1\% do rendimento final, na média das três cultivares. Com a aplicação do $\mathrm{N}$ no emborrachamento, este percentual caiu para 26,5\%. A cultivar "BRS 179" foi aquela em que os afilhos menos contribuíram para o rendimento final.

Segundo ALMEIDA et al. (2002), um dos motivos da baixa produtividade média das lavouras de trigo no Brasil é a pequena participação dos afilhos na formação do rendimento final. Sendo assim, a emissão, o desenvolvimento e a sobrevivência dos afilhos são importantes, pois essas estruturas fazem parte dos componentes do rendimento e são também supridoras de assimilados ao colmo principal. Os dados obtidos neste trabalho indicam que, independentemente do genótipo, a aplicação precoce de nitrogênio é importante para a emissão e sobrevivência dos afilhos, bem como para que a taxa de desenvolvimento destes seja similar a do colmo principal, o que é fundamental para que os afilhos possam contribuir, incrementando o rendimento de grãos (ALMEIDA \& MUNDSTOCK, 1998).

O teor de proteína nos grãos variou entre 15,38 e 23,42\%, dependendo do tratamento (Tabela 4). A cultivar "Rubi" apresentou um teor de proteína nos grãos maior do que a cultivar "Fundacep 36", na média das quatro épocas de aplicação de $\mathrm{N}$ em cobertura, sem diferir significativamente da cultivar "BRS 179”. Comparando-se o teor protéico dos grãos na colheita com os valores de rendimento de grãos (Tabelas 2 e 4), observa-se que houve comportamento oposto das duas variáveis. A cultivar mais produtiva (“Fundacep 36”) foi a de menor teor de proteína nos grãos e a cultivar com grãos mais protéicos ("Rubi”) foi a de menor rendimento. Esses dados confirmaram as observações feitas por FOWLER (2003) e SOUZA et al. (2004), sendo explicados pelo maior gasto energético que a planta apresenta para formação de proteínas, o qual pode comprometer o acúmulo de carboidratos nos grãos.

Não houve efeito significativo da época de aplicação de nitrogênio sobre o teor de proteína nos grãos das três cultivares avaliadas. Isso contrariou as observações feitas por GARRIDO-LESTACHE et al. (2004) de que o atraso na aplicação de nitrogênio favorece o aumento do teor protéico dos grãos, sendo este incremento maior do que o aumento verificado no rendimento de grãos.

\section{CONCLUSÕES}

A aplicação precoce de nitrogênio em cobertura, nos estádios 3,5 e 5,5 da escala HAUN, propicia a obtenção de maior produtividade de trigo e maior participação dos afilhos no rendimento de grãos, independentemente das características genéticas, morfológicas e fenológicas da cultivar.

A época de aplicação do nitrogênio em cobertura não interfere no teor de proteína no grão das cultivares “Fundacep 36”, “Rubi” e "BRS 179”. A cultivar "Fundacep 36” é mais produtiva e apresenta menor teor de proteína nos grãos do que as cultivares “RUBI” e "BRS 179”.

Tabela 4 - Porcentagem de proteína bruta nos grãos de três cultivares de trigo, em quatro épocas de aplicação de nitrogênio em cobertura. Lages, 2003.

\begin{tabular}{|c|c|c|c|c|}
\hline Época & Fundacep 36 & Rubi & BRS 179 & Média \\
\hline & \multicolumn{4}{|c|}{ Proteína bruta } \\
\hline $3,5^{1 /}$ & 17,05 & 22,16 & 15,38 & $18,20 \mathrm{~ns}^{2 /}$ \\
\hline 5,5 & 16,31 & 18,03 & 23,42 & 19,25 \\
\hline 7,5 & 16,08 & 21,47 & 18,60 & 18,72 \\
\hline Emborr. & 19,63 & 19,52 & 17,36 & 18,84 \\
\hline Média & $17,27 b^{3 /}$ & $20,30 \mathrm{a}$ & $18,69 a b$ & \\
\hline CV (\%) & \multicolumn{4}{|c|}{7,4} \\
\hline
\end{tabular}

\footnotetext{
${ }^{1 /}$ Estádios 3,5, 5,5, 7,5 e emborrachamento da escala proposta por HAUN (1973).

${ }^{2 /}$ ns: diferença não-significativa.

${ }^{3 /}$ Médias seguidas pela mesma letra minúscula na linha não diferem estatisticamente pelo Teste de Duncan a 5\% de probabilidade de erro.
} 


\section{REFERÊNCIAS}

ABDIN, M.Z. et al. Effect of split nitrogen application on growth and yield of wheat (T. aestivum L.) genotypes with different N-assimilation potential. Journal of Agronomy and Crop Science, Madison, v.176, p.83-90, 1996.

ALMEIDA, M.L. et al. Cultivares de trigo respondem diferentemente à qualidade da luz quanto à emissão de afilhos e acumulação de massa seca. Ciência Rural, Santa Maria, v.32, p.377-383, 2002.

ALMEIDA, M.L.; MUNDSTOCK, C.M. O afilhamento em comunidades de cereais de estação fria é afetado pela qualidade da luz? Ciência Rural, Santa Maria, v.28, p.511-519, 1998.

COMISSÃO DE FERTILIDADE DO SOLO - RS/SC. Recomendações de adubação e calagem para os estados do Rio Grande do Sul e Santa Catarina. 3.ed. Passo Fundo: SBCS - Núcleo Regional Sul, 1995. 223p.

COMISSÃO SUL-BRASILEIRA DE PESQUISA DE TRIGO, 35, 2003, Passo Fundo. Recomendações técnicas para a cultura do trigo. Passo Fundo: CBPT, 2003. 119p.

DIDONET, A.D. et al. Realocação de nitrogênio e de biomassa para os grãos, em trigo submetido a inoculação de Azospirillum. Pesquisa Agropecuária brasileira, Brasília, v.35, p.401411, 2000.

EMBRAPA. Centro Nacional de Pesquisa de Solos. Sistema Brasileiro de Classificação de Solos. Brasília: EMBRAPA, 1999. 412p.

ERNANI, P.R. Disponibilidade de nitrogênio e adubação nitrogenada pra a macieira. Lages: Graphel, 2003. 76p.

FOWLER, D.B. Crop nitrogen demand and grain protein concentration of spring and winter wheat. Agronomy Journal, Madison, v.95, p.260-265, 2003.

GARRIDO-LESTACHE, E. et al. Effect of $\mathrm{N}$ rate, timing and splitting and $\mathrm{N}$ type on bread-making quality in hard red spring wheat under rainfed Mediterranean conditions. Field Crops Research, Amsterdan, v.85, p.213-236, 2004.

HARPER, J.E. Nitrogen metabolism. In: BOOTE, K.J. et. al. Physiology and determination of crop yield. American Society of Agronomy, 1994. Cap.11A, p.285-302.

HAUN, J.R. Visual quantification of wheat development. Agronomy Journal, Madison, v.65, p.116-119, 1973.

INSTITUTO BRASILEIRO DE GEOGRAFIA E ESTATÍSTICA. Levantamento sistemático da produção agrícola. Capturado em 17 de abril de 2004. Online. Disponível na Internet: http//www.ibge.gov.br.

MAHLER, R.L. et. al. Soils. Nitrogen source, timing of application, and placement: effects on winter wheat production. Agronomy Journal, Madison, v.86, p.637-642, 1994.

MASCHIO, J. Boom do agronegócio eleva safra de trigo. Agência Folha. Londrina. Capturado em 06 de julho de 2004. Online. Disponível na Internet: http//www.consultores.com.br.

MUNDSTOCK, C.M. Planejamento e manejo integrado da lavoura de trigo. Porto Alegre: Evnagraf, 1999. 227p.

OKUYAMA, L.A. et. al. Correlation and path analysis of yield and its components and plant traits in wheat. Ciência Rural, Santa Maria, v.34, p.1701-1708, 2004.

SOUZA, E.J. et. al. Influence of genotype, environment, and nitrogen management on spring wheat quality. Crop Science, Madison, v.44, p.425-432, 2004.

SILVA, P.R.F. da et al. Grain yield and kernel protein content increases of maize hybrids with late nitrogen side-dresses. Scientia Agrícola, Piracicaba, v.62, p.487-492, 2005.

TEDESCO, M.J. et al. Análise de solo, plantas e outros materiais. Porto Alegre: Departamento de Solos, Faculdade de Agronomia, UFRGS, 1995. 174p. (Boletim Técnico, 5). 